\title{
Perdas de solo e de água em diferentes sistemas de manejo em Latossolo Vermelho
}

\author{
Stanley Vaz dos SANTOS ${ }^{1 *}$, Eva de Melo FERREIRA², Nori Paulo GRIEBELER ${ }^{3}$, \\ Wilson Mozena LEANDRO ${ }^{3}$
}

\footnotetext{
${ }^{1}$ Instituto Brasileiro do Meio Ambiente e dos Recursos Naturais Renováveis, Superintendência Regional no Goiás, Goiânia, GO, Brasil. ${ }^{2}$ Programa de Pós-Graduação em Saneamento, Meio Ambiente e Recursos Hídricos, Universidade Federal de Minas Gerais, Belo Horizonte, MG, Brasil. ${ }^{3}$ Departamento de Agricultura, Escola de Agronomia, Universidade Federal de Goiás, Goiânia, GO, Brasil. *E-mail: stanleyagro@hotmail.com
}

Recebido em janeiro/2018; Aceito em julho/2018.

RESUMO: O objetivo foi comparar as perdas de água e solo em diferentes sistemas de manejo, bem como determinar parâmetros de clima e de solo que possam estar associados a essas perdas e estimar perdas de solo por meio de modelos matemáticos. A área experimental consiste em 10 parcelas de $20 \mathrm{~m}^{2}(10 \times 2 \mathrm{~m})$, das quais nove foram trabalhadas inicialmente no sistema de plantio direto (SPD) e uma utilizada no sistema convencional (CO). Nestes moldes foram quantificadas as perdas de solo e água em diferentes safras. No final do segundo ano, das parcelas com SPD, cinco foram mantidas neste sistema, duas foram revolvidas na profundidade de $25 \mathrm{~cm}$ e reiniciadas no SPD e, em duas foi utilizado o sistema CO. Antes da utilização como sistema convencional, a parcela CO possuía plantio direto. Nas três safras estudadas o percentual infiltrado foi superior a 93\% para o SPD e a $71 \%$ para o $\mathrm{CO}$, considerando apenas as chuvas que propiciaram escoamento. As médias das perdas de solo na segunda safra foram de 2,$27 ; 2,51 ; 14.61$; e $14,79 \mathrm{t} \mathrm{ha}^{-1} \mathrm{e}$, de água, de 3,$07 ; 5,51 ; 14,04$; e $10,80 \%$, respectivamente para os sistemas de manejo SPD, CO e PDI.

Palavras-chave: erosão hídrica, modelos de predição, erosividade.

\section{Soil and water losses in different management systems in red latosol}

\begin{abstract}
The objective was to compare soil and water losses in different management systems, as well as determine soil and climate parameters that could be associated with these losses and estimate soil losses through mathematical models. The experimental area consists of 10 plots of $20 \mathrm{~m} 2(10 \times 2 \mathrm{~m})$, of which nine were initially worked in the no-tillage system (SPD) and one in the conventional system (CO). Soils and water losses in different crops were quantified in these models. At the end of the second year, of the plots with SPD, five were kept in this system, two were revolved at $25 \mathrm{~cm}$ depth and restarted in the SPD and in two the CO system was used. Prior to use as a conventional system, the CO plot had no-tillage. In the three harvests studied, the percentage infiltrated was greater than $93 \%$ for the SPD and $71 \%$ for the CO, considering only the rains that caused the runoff. The average soil loss in the second harvest was $2.27 ; 2.51 ; 14.61$; and $14.79 \mathrm{t} \mathrm{ha}^{-1}$ and, by water, 3.07; 5.51; 14.04; and 10.80\%, respectively for the SPD, CO and PDI management systems.
\end{abstract}

Keywords: hydric erosion, models of prediction, erosivity.

\section{INTRODUÇÃO}

Diversos fatores são determinantes na perda de solo, sendo a erosão hídrica uma das principais causadoras de alterações negativas em determinado meio natural ou antropizado. $\mathrm{O}$ uso e o manejo do solo alteram as forças de resistência a desagregação, especialmente as operações de preparo do solo que envolve uma mobilização do solo maior ou menor, exercendo influência sobre a estabilidade dos agregados (OLIVEIRA et al., 2012).

$\mathrm{O}$ aumento da pressão sobre os recursos de solo e água tem ocasionado discordâncias entre os habitantes de bacias hidrográficas, uma vez que atividades praticadas em determinado local podem ter efeitos negativos em outra área (HUNINK et al., 2012). O processo de erosão hídrica ocorre também em bacias hidrográficas em todo o mundo, com as modificações de ecossistemas naturais causando intensa degradação ambiental em diferentes áreas abrangidas.

A erosão em estágios avançados, transporta sedimentos, remove nutrientes e agroquímicos para fora dos sistemas agrícolas. Isso resulta no decréscimo de produtividade
(AVANZIET et al., 2013). As ravinas e sucos são parte dos resultados provenientes dos processos erosivos. Em culturas agrícolas, o tipo de raízes e folhas, ângulo de inserção das folhas no colmo, quantidade e espessura das hastes e do hábito de crescimento da planta afetam a erosão hídrica, interceptam as gostas de precipitadas (BERTOL et al., 2013).

Com o uso de chuvas simuladas em diferentes estágios da cultura, é possível avaliar o efeito das condições físicas de superfície do solo, criadas por métodos de seu preparo, nas perdas de solo e água por erosão hídrica (VOLK; COGO, 2014). Marioti et al., (2013) quantificou as perdas de água e solo por erosão hídrica, em um solo cultivado com soja e milho sob semeadura direta, nas direções do pendente e em contorno ao declive. Nesse trabalho a cultura do milho foi mais eficaz no controle das perdas de solo do que a soja, independentemente da forma de semeadura, e ambas foram mais eficazes do que a testemunha.

A erosão do solo é um risco tradicionalmente associado à agricultura, tendo efeitos a médio e longo prazos sobre a produtividade do solo e sustentabilidade agrícola. Além disso, 
pode contribuir para a poluição dos recursos hídricos carreando defensivos químicos presentes no solo, e o assoreamento, provocando inundações não só nas áreas rural (SHI et al., 2012). No intuito de minimizar os problemas mencionados, diversos trabalhos têm apresentado os efeitos benéficos das coberturas vegetais no processo de conservação do solo (LU et al., 2013).

Tendo em vista o rápido crescimento da agricultura na região do cerrado e a escassez de informações sobre os impactos ambientais causados pelo uso agrícola do solo, este trabalho teve como objetivos: comparar as perdas de água e solo em diferentes sistemas de manejo, bem como determinar parâmetros de clima e de solo que possam estar associados a essas perdas, e estimar perdas de solo por meio de modelos matemáticos.

\section{MATERIAL E MÉTODOS}

A área experimental foi implantada em Latossolo Vermelho distroférrico, de textura argilosa (Embrapa, 2006), relevo caracterizado como moderadamente plano a levemente ondulado.

O clima enquadra-se como B2 WB 42' (LOBATO, 1978), com temperatura média de $21^{\circ} \mathrm{C}$, precipitação pluviométrica média anual de $1487 \mathrm{~mm}$, apresentando períodos secos e chuvosos bem definidos e declividade média de 5,03\% (coordenadas geográficas $16^{\circ} 36^{\prime} 00^{\prime \prime} \mathrm{S} 49^{\circ} 16^{\prime} 57^{\prime \prime} \mathrm{W}$ ). A área experimental foi composta por 10 parcelas de $10 \times 2 \mathrm{~m}(20$ $\mathrm{m}^{2}$ ). Antes da implantação das parcelas, toda a área foi preparada com grade de arado e niveladora. As parcelas foram individualizadas por meio de placas de zinco com $30 \mathrm{~cm}$ de altura (dos quais $10 \mathrm{~cm}$ foram enterrados no solo).

Na parte inferior de cada parcela foi instalado um sistema para coleta e condução do escoamento superficial com dois tambores com capacidade para 160 L. O primeiro tambor era conectado ao segundo por meio de um sistema separador, com relação 4/1, sendo apenas $1 / 5$ da vazão excedente do primeiro tambor conduzida ao segundo (Figuras 1 e 2).

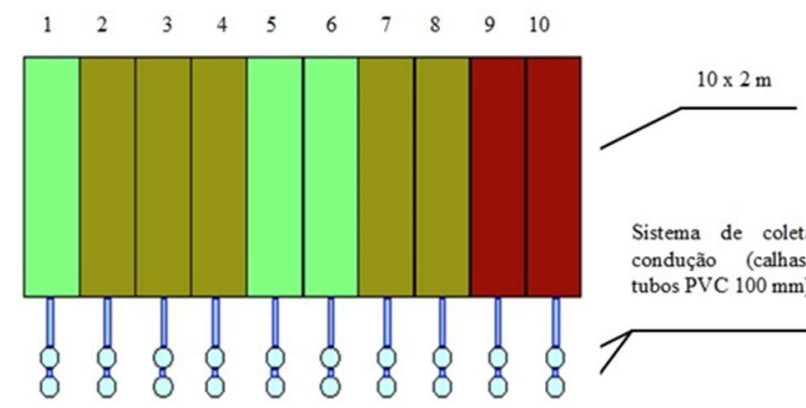

Figura 1. Representação esquemática e sistemas de preparo de solo nas parcelas na safra 2003/2004. PD: Plantio Direto; PDR: Plantio Direto Reiniciado; PDI: Plantio Direto iniciado; CO: Cultivo Convencional.

Figure 1. Schematic representation and soil preparation systems in the 2003/2004 crop plots. NTS: No-tillage system; NTSR: No-tillage system Reboot; NTSS: No-tillage system started; CC: Conventional Cultivation.

Inicialmente, nove das parcelas foram inseridas no sistema plantio direto (SPD) e uma no sistema convencional (CO) durante os dois primeiros anos de estudo, chamada de Fase 1 (Tabela 1). Para a safra 2003/2004, chamada de Fase 2, foi realizada uma nova distribuição das parcelas, ao acaso, sendo que, das parcelas inicialmente cultivadas no SPD, permaneceram apenas cinco em que o solo não foi revolvido (PD). Duas parcelas foram reiniciadas no sistema de plantio direto (PDR), duas parcelas deixaram o sistema de plantio direto e passaram para o sistema de cultivo convencional $(\mathrm{CO})$ e a parcela inicialmente em cultivo convencional foi iniciada no Plantio Direto (PDI).

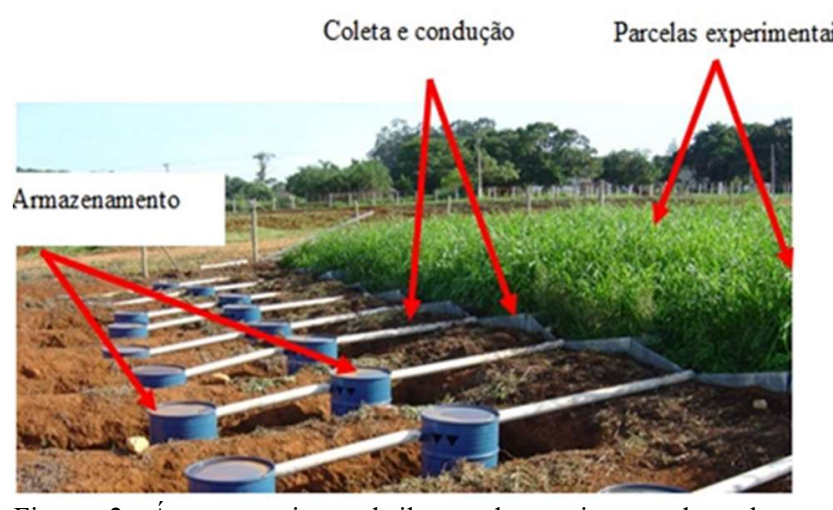

Figura 2. Área experimental ilustrando o sistema de coleta, a condução e o armazenamento do escoamento nas parcelas cultivadas com milheto.

Figure 2. Experimental area illustrating the system of collection, conduction and storage of the flow in the plots cultivated with millet.

Na segunda fase as parcelas permaneceram em pousio até o plantio do milheto (Pennisetum americanum) realizado em todas as parcelas. Após, foi feito o plantio de algodão (Gossypium sp.) variedade Aroeira. Para a estimativa das perdas de solo nos diferentes sistemas de manejo foi utilizada a Equação Universal de Perdas de Solo (EUPS) (Equação 1), proposta por Wischmeier; Smith (1978):

$$
A=R K L S C P
$$

(Equação 1)

em que $\mathrm{A}=$ perda de solo por unidade de área $\left(\mathrm{Mg} \mathrm{ha}^{-1}\right) ; \mathrm{R}=$ fator de erosividade da chuva (MJ mm ha- $\left.{ }^{-1} \mathrm{~h}^{-1}\right) ; \mathrm{K}=$ fator de erodibilidade do solo $\left(\mathrm{t} \mathrm{h} \mathrm{MJ}-1 \mathrm{~mm}^{-1}\right) ; \mathrm{L}=$ fator comprimento de rampa $(\mathrm{m}) ; \mathrm{S}=$ fator de declividade (\%); $\mathrm{C}$ = fator uso e manejo do solo, adimensional; e $\mathrm{P}=$ fator prática conservacionista, adimensional.

As erosividades das chuvas $(\mathrm{R})$ foram determinadas por dados pluviométricos de estação meteorológica da UFG, com a análise das chuvas de agosto de um ano a julho do ano decorrente, nas três safras utilizadas e para a média dos dados do período de 1975 a 2002 . No período de um ano foram analisados os diagramas pluviométricos, com o objetivo de determinar a intensidade das chuvas.

O método utilizado para cálculo da erosividade das chuvas foi proposto por Wischmeier; Smith (1958), com base nos valores de precipitação pluvial média mensal e anual (Equação 2). $O$ índice de erosividade média anual foi calculado utilizando os valores médios mensais de erosividade.

$$
E I_{30}=67,355\left(r^{2} / P\right)^{0,85}
$$

(Equação 2)

em que: EI30 = média mensal da erosividade $\left(\mathrm{MJ} \mathrm{mm} \mathrm{ha}^{-1} \mathrm{~h}^{-1}\right) ; \mathrm{r}=$ precipitação pluvial média mensal $(\mathrm{mm})$; e $\mathrm{P}=$ precipitação pluvial média anual $(\mathrm{mm})$.

A erodibilidade foi estimada por modelos baseados em atributos físicos do solo, tais como a densidade. Foram 
utilizados os modelos propostos por Wischmeier et al. (1971) (Equação 3), Denardin (1990) (Equação 4) e Roloff; Denardin (1994) (Equação 5) e o valor de erodibilidade encontrado em Silva et al. (1997) para um Latossolo Vermelho da região de Goiânia - 0,009 Mg h MJ-1 $\mathrm{mm}^{-1}$ :

$$
\begin{array}{r}
K=\left\{\left[2,\left(10^{-4}\right)(12-M O) M^{1,14}+3,25(E S T-2)+2,5(P E R-3)\right] / 100\right) 0,1317 \\
\text { (Equação 3) }
\end{array}
$$

em que $\mathrm{K}=$ erodibilidade do solo $\left(\mathrm{Mg} \mathrm{h} \mathrm{MJ}^{-1} \mathrm{~mm}^{-1}\right) ; \mathrm{M}=$ percentual da soma dos teores de silte e areia muito fina multiplicada por $100 \mathrm{e}$ subtraído o teor de argila. $\mathrm{MO}=$ teor de matéria orgânica determinada na camada de 0-5 cm; EST e PER = códigos correspondentes à estrutura e permeabilidade do solo, adimensionais. Para a análise de textura utilizou-se $\mathrm{NaOH} 1 \mathrm{~mol} \mathrm{~L}^{-1}$ como dispersante (Embrapa, 1997).

$K=0,006084(P E R)+0,00834286(M O)-0,00116162(A L)-0,00037756(P A R T)$

(Equação 4)

em que: $\mathrm{Al}$ = teor de $\mathrm{A} 12 \mathrm{O} 3$ da fração TFSA, por ataque sulfúrico $(\mathrm{g}$ $\left.\mathrm{kg}^{-1}\right)$; PART $=$ percentagem de partículas de diâmetro compreendido entre 0,5 e $2,0 \mathrm{~mm}$ (areia grossa e muito grossa), determinado por $\mathrm{NaOH} 1 \mathrm{~mol} \mathrm{~L}^{-1}$.

$$
K=0,0049 P E R+0,0331 \mathrm{Mm}^{0,5}
$$

$\mathrm{Mm}=$ corresponde ao produto do teor de silte $\left(\mathrm{g} \mathrm{kg}^{-1}\right)$ pela soma de silte e areia fina $\left(\mathrm{g} \mathrm{kg}^{-1}\right)$, sendo a análise granulométrica realizada com $\mathrm{NaOH} 1 \mathrm{~N}$. O comprimento de rampa (L) e a declividade (S) foram calculados a partir das equações de Wischmeier; Smith (1978) (Equação 6) e Bertoni; Lombardi Neto (1999) (Equação 7):

$$
L S=L^{0,5}\left(0,76+0,53 S+0,076 S^{2}\right) / 55,209
$$

$$
L S=0,00984 S^{1,18} L^{0,63}
$$

em que: L corresponde ao comprimento da rampa $(10 \mathrm{~m})$ e $\mathrm{S}$, a declividade determinada individualmente para cada parcela. Os valores de $\mathrm{C}$ foram 0,314 para o SPD, PDI e PDR, e de 0,392 para o $\mathrm{CO}$; os de $\mathrm{P}$ foram iguais a 0,640 para todas as (Margolis et al., 1985).
A água escoada e o solo transportado foram quantificados para o volume de chuvas que propiciou o escoamento superficial. Com o volume de água escoado superficialmente e o volume total precipitado, obtido nos dados pluviométricos da estação climatológica, foi possível determinar a quantidade de água infiltrada. As perdas de solo foram determinadas pela quantificação dos sedimentos contidos nos tambores, agitando-se a água com os sedimentos para homogeneizar o material e coletando-se $1 \mathrm{~L}$ em cada tambor.

Foram coletados 23 pontos em cada parcela, divididos em três colunas e seis linhas, sendo um coletado entre as linhas, para o levantamento das características do relevo com nível ótico. Com os pontos, foi gerado um arquivo texto, no formato $\mathrm{X}, \mathrm{Y}, \mathrm{Z}$, em que $\mathrm{X}$ e $\mathrm{Y}$ correspondem às posições do ponto de coleta e $\mathrm{Z}$ o valor da cota, reproduzindo-se a conformação da superfície das parcelas. A conformação da superfície foi levantada como possível indicativo de perda de solo dentro e entre de sistemas de cultivos.

$\mathrm{Na}$ Fase 2 o experimento, realizou-se a análise do desenvolvimento da cultura em cada parcela, após abertura das maças do algodoeiro, sendo isso essencial para determinar os níveis de produtividade das plantas avaliadas durante 0 experimento. Foram avaliados: a altura das plantas, determinada em três plantas por parcela e ao acaso; o número de plantas por metro linear, contando-se as plantas de algodão por metro linear no meio da parcela; o desenvolvimento foliar da planta, $o$ ataque de pragas, $o$ ataque de doenças e a cobertura morta do solo.

Estas notas seguiram a escala de 0 (zero), para sem desenvolvimento ou ocorrência, a 5 (cinco), para o maior desenvolvimento ou ocorrência, tendo como base 0 desenvolvimento normal numa lavoura comercial. Essa escala foi desenvolvida pelos autores. Para a produtividade relativa foi atribuído o valor de $100 \%$ para a parcela com o melhor

\begin{tabular}{|c|c|c|c|c|c|c|c|c|c|}
\hline \multicolumn{2}{|c|}{4} & \multicolumn{2}{|l|}{ Safra 1} & \multicolumn{2}{|c|}{ Safra 2} & \multicolumn{2}{|l|}{ Safra 3} & \multicolumn{2}{|c|}{ Safra 4} \\
\hline Fase 1 & Fase 2 & Verão & Safrinh & Verão & Safrinha & Verão & Safrinha & Verão & Safrinha \\
\hline 4 & PD1 & Braquiária + sorgo & Arroz & Arroz & Pousio & Pousio & Soja & Milheto & Algodão \\
\hline 7 & PD2 & Braquiária + crotalária & Pousio & Milho & Pousio & Braquiária + & Soja & Milheto & Algodão \\
\hline 8 & PD3 & Milheto+ crotalária & Pousio & Arroz & Pousio & Milheto+ crotalária & Soja & Milheto & Algodão \\
\hline 2 & PD4 & Milheto & Pousio & Milho & Pousio & Milheto & Milho & Milheto & Algodão \\
\hline 3 & PD5 & Crotalária & Arroz & Arroz & Pousio & Braquiária & Soja & Milheto & Algodão \\
\hline 5 & PDR1 & Feijão guandu & Pousio & Milho & Pousio & Feijão guandu & Arroz & Milheto & Algodão \\
\hline 6 & PDR2 & Mucuna & Pousio & Arroz & Pousio & Mucuna & Milho & Milheto & Algodão \\
\hline 1 & PDI & Sem cobertura & Arroz & Soja & Pousio & Sem cobertura & Arroz & Milheto & Algodão \\
\hline 9 & $\mathrm{CO} 1$ & Braquiária & Arroz & Soja & Pousio & Crotalária & Arroz & Milheto & Algodão \\
\hline 10 & $\mathrm{CO} 2$ & Erva daninha & Arroz & Soja & Pousio & Braquiária & Arroz & Milheto & Algodão \\
\hline
\end{tabular}
desenvolvimento, fornecendo às outras parcelas valores percentuais comparativos.

Tabela 1. Sistemas de rotação e sucessão de culturas cultivadas nas parcelas experimentais. Table 1. Systems of rotation and succession of cultivated crops in the experimental plots.

(1) Fase 1: corresponde aos dois anos iniciais; Fase 2: corresponde aos dois anos finais. PD: Plantio Direto; PDR: Plantio Direto Reiniciado; PDI: Plantio Direto iniciado a partir do convencional; CO: Plantio Convencional. Sendo 1,2,3 e 4 em PD1 e PD2as diferenças fases de acordo com o sistema de Plantio Direto.

\section{RESULTADOS}

\subsection{Regras gerais}

$\mathrm{Na}$ Tabela 2 são apresentados os percentuais de escoamento das águas das chuvas que propiciaram perdas de solo para as três safras estudadas no período de agosto a julho. Dos 1595, 1409 e $1640 \mathrm{~mm}$, respectivamente para as referidas safras, tem-se que 600,$80 ; 854,20$ e $1138,30 \mathrm{~mm}$ tiveram potencial erosivo.

No SPD, a parcela PD5 apresenta modelagem mais abrupta, indicando caminhos preferenciais que podem ter incrementado a perda de solo quando comparada com as parcelas PD1, PD2 e PD3. A parcela PD4 aparenta caminhos 
preferenciais a incrementar a perda de solo, porém com modelagem mais amena em comparação com a PD5.

A influência da modelagem fica mais explícita no sistema de plantio convencional. A parcela $\mathrm{CO} 1$ aparenta favorecer a perda de solo e água em detrimento à parcela $\mathrm{CO}^{2}$. Em análise das imagens, a modelagem da superfície (topografia) influenciou as perdas de solo e água por caminhos preferenciais. Porém, deve-se ter cautela nas afirmações uma vez que o comprimento de rampa das parcelas é de apenas 10 $\mathrm{m}$, podendo ocasionar mudanças abruptas na interferência desse atributo.
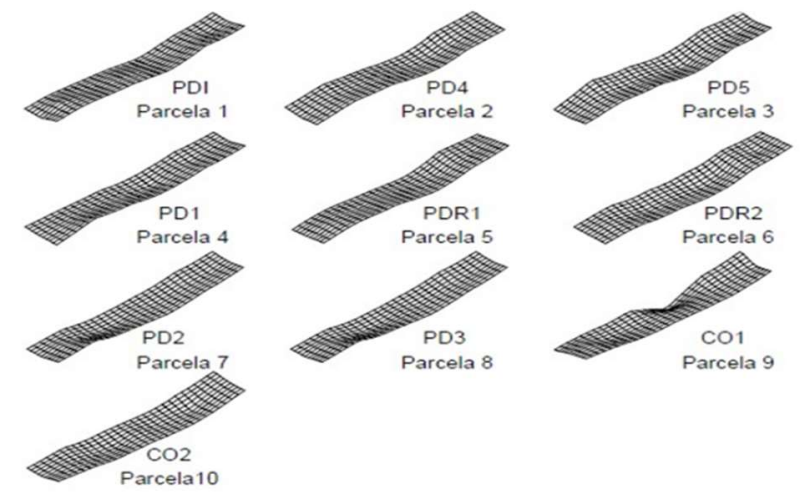

Figura 3. Modelagem do relevo das parcelas experimentais levantadas por meio de nível ótico na terceira safra utilizada no estudo.

Figure 3. Modeling of the relief of experimental plots raised by optical level in the third harvest used in the study.
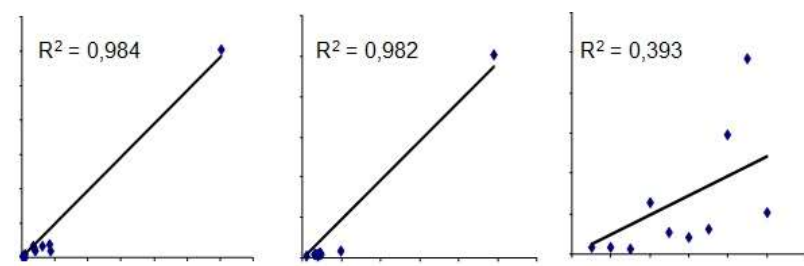

Figura 4. Correlações entre o volume de água escoada da chuva e a perda de solo nos três anos estudados.

Figure 4. Correlations between the volume of water drained from the rainfall and the loss of soil in the three years studied.

A influência dos indicadores de sustentabilidade, principalmente da cobertura vegetal, e da topografia da parcela são relevantes no experimento. Entretanto, o sistema de manejo do solo, analisado por safra individualizada, foi o principal fator nas perdas de solo e água. Na primeira safra, o sistema de plantio direto acarretou a perda de solo média de 0,104 t ha-1 de solo; o sistema de plantio convencional ocasionou perda média de 3,025 t ha-1. Valor na proporção de $1: 28,99$ entre o PD e o CO.

$\mathrm{Na}$ segunda safra, o sistema de plantio convencional obteve incremento na perda de solo chegando a 10,1 t ha- 1 . Esse fato está diretamente relacionado ao aumento de chuvas erosivas, ocorrendo o mesmo com o sistema de plantio direto, com média de 0,180 t ha-1 de solo erodido, correspondendo a 1:56 entre o PD e o CO. Esses resultados reforçam a maior eficiência da cobertura vegetal no sistema de plantio direto em comparação à segunda safra, mesmo com o aumento na perda de solo.

Tabela 2. Valores de perdas de solo, de escoamento das águas das chuvas erosivas e seu percentual para a primeira, segunda e terceira safra. Table 2. Values of soil losses, drainage of erosion rains and their percentage for the first, second and third harvests.

\begin{tabular}{|c|c|c|c|c|c|c|c|c|c|c|}
\hline \multicolumn{2}{|c|}{ Sistema $^{(1)}$} & \multicolumn{3}{|c|}{ Primeira safra ${ }^{(2)}$} & \multicolumn{3}{|c|}{ Segunda safra } & \multicolumn{3}{|c|}{ Terceira safra } \\
\hline \multirow[t]{2}{*}{ Fase 1} & \multirow[t]{2}{*}{ Fase 2} & \multirow{2}{*}{$\begin{array}{c}\begin{array}{c}\text { Perda de } \\
\text { solo }\end{array} \\
\text { t ha }^{-1}\end{array}$} & \multicolumn{2}{|c|}{$\begin{array}{l}\text { Escoamento de } \\
\text { água de chuva }\end{array}$} & \multirow{2}{*}{$\begin{array}{c}\text { Perda de solo } \\
\mathrm{tha}^{-1}\end{array}$} & \multicolumn{2}{|c|}{$\begin{array}{l}\text { Escoamento de } \\
\text { água de chuva }\end{array}$} & \multirow{2}{*}{$\begin{array}{c}\text { Perda de solo } \\
\text { t ha }^{-1}\end{array}$} & \multicolumn{2}{|c|}{$\begin{array}{l}\text { Escoamento de } \\
\text { água de chuva }\end{array}$} \\
\hline & & & $\mathrm{mm}$ & $\%$ & & $\mathrm{~mm}$ & $\%$ & & $\mathrm{~mm}$ & $\%$ \\
\hline 4 & PD1 & 0,174 & 13 & 2,11 & 0,163 & 17 & 1,94 & 0,872 & 21 & 1,83 \\
\hline 7 & PD2 & 0,105 & 8 & 1,38 & 0,152 & 17 & 1,94 & 0,859 & 31 & 2,7 \\
\hline 8 & PD3 & 0,013 & 1 & 0,08 & 0,045 & 5 & 0,63 & 0,596 & 15 & 1,3 \\
\hline 2 & PD4 & 0,152 & 8 & 1,27 & 0,204 & 23 & 2,74 & 6,398 & 78 & 6,87 \\
\hline 3 & PD5 & 0,167 & 7 & 1,13 & 0,278 & 23 & 2,73 & 2,664 & 30 & 2,64 \\
\hline 5 & PDR1 & 0,100 & 18 & 2,94 & 0,166 & 20 & 2,29 & 2,030 & 45 & 3,91 \\
\hline 6 & PDR2 & 0,046 & 2 & 0,29 & 0,067 & 20 & 2,36 & 2,996 & 82 & 7,2 \\
\hline $1^{(3)}$ & PDI & 3,025 & 121 & 20,0 & 10,111 & 245 & 28,68 & 14,792 & 123 & 10,8 \\
\hline 9 & $\mathrm{CO} 1$ & 0,180 & 17 & 2,75 & 0,353 & 50 & 5,83 & 24,145 & 186 & 16,32 \\
\hline 10 & $\mathrm{CO} 2$ & 0,002 & 2 & 0,35 & 0,195 & 17 & 1,97 & 5,080 & 134 & 11,75 \\
\hline
\end{tabular}

(1) Fase 1: corresponde aos dois anos iniciais; Fase 2: corresponde aos dois anos finais. PD: Plantio Direto; PDR: Plantio Direto

\section{DISCUSSÃO}

A quantificação dos volumes e percentuais das águas das chuvas infiltradas foi realizada por diferença entre o volume precipitado e o escoado. Em praticamente todas as parcelas avaliadas a quantidade de água infiltrada foi acima de $80 \%$. Estes valores são significativos, pois foram analisadas apenas as chuvas que propiciaram perda de água em uma ou mais parcelas e refletem uma infiltração superior a 11.000 .000 (onze milhões) de litros de água precipitados para um hectare. A terceira safra estudada obteve a menor precipitação anual calculada.

Os valores escoados de 121, 245 e $123 \mathrm{~mm}$ para a parcela um inferem nos valores infiltrados de 79,94 e 71,32 \% com cultivo convencional e de $85,21 \%$ com a mudança para o sistema de plantio direto. Aumento no percentual infiltrado da água precipitada com a mudança do sistema cultivo da primeira e segunda safra para a terceira.

Os maiores índices de infiltração foram no sistema PD, mesmo na primeira safra nas parcelas que passaram para 0 sistema PDR tendo o solo revolvido (Quadro 2), indicando o SPD como mais eficiente no aproveitamento da água da chuva. Nas primeiras safras registraram-se menores perdas de solo e água em relação à terceira safra. Entretanto, observou-se maior proporção de perda de solo para o sistema de plantio convencional em detrimento ao sistema de plantio direto.

Quanto à cobertura vegetal fica evidente que as espécies cultivadas nas primeiras safras propiciaram menor perda de água e solo, o que permite inferir que as gramíneas e as leguminosas utilizadas foram mais eficientes que o algodoeiro em cobertura vegetal para proteção do solo em processos 
erosivos. Entretanto, deve-se salientar que o volume precipitado em relação ao tempo foi maior na última safra, aumentando, assim, os valores obtidos de perda de solo e de escoamento de água.

Nas parcelas um, dois e três a cobertura morta decorrente dos resíduos do milheto apresentou, em relação às outras parcelas, maior declínio na quantidade de palha ao longo do experimento. Constatou-se também que no SPD as maiores diferenças de perda de cobertura morta ocorreram até a fase intermediária da cultura, amenizando no final do ciclo.

Os indicadores de sustentabilidade estabelecidos para a cultura do algodoeiro no sistema de plantio direto nas parcelas
PD4 e PD5 corroboram para a maior perda de solo e água cujos valores foram os menores em relação aos demais sistemas (Tabela 3). Também nas parcelas nove e 10, no sistema de cultivo convencional $\mathrm{CO} 1$ e $\mathrm{CO} 2$, a influência da cobertura vegetal está explícita nos menores valores encontrados. No $\mathrm{CO} 2$, observou-se menor perda de solo nos períodos iniciais, no entanto, as perdas de água e solo aumentaram nas últimas precipitações. Este fato deve estar relacionado a problemas de manejo da parcela, que apresentou alta infestação de tiririca durante boa parte do período inicial analisado, o que alterou os caminhos para passagem da água.

Tabela 4. Estimativas das perdas de solo usando a Equação Universal de Perdas de Solo (EUPS) por diferentes modelos de erosividade, erodibilidade e fator LS, com os fatores C e P para a cultura do algodão conforme Margolis et al. (1985). Safra 2003/2004.

Table 4. Estimates of soil losses using the Universal Soil Loss Equation (USLE) by different erosivity, erodibility and SL factor models, with the $\mathrm{C}$ and $\mathrm{P}$ factors for the cotton crop according to Margolis et al. (1985). Harvest 2003/2004.

\begin{tabular}{|c|c|c|c|c|c|c|c|c|}
\hline \multirow[t]{2}{*}{ Sistema $^{(1)}$} & \multicolumn{4}{|c|}{ Erosividade $^{(2)}$} & \multicolumn{4}{|c|}{ ErosividadeB $^{(3)}$} \\
\hline & $\begin{array}{c}\text { Wischmeier et al. } \\
(1971)\end{array}$ & $\begin{array}{c}\text { Denardin } \\
(1990)\end{array}$ & $\begin{array}{c}\text { Roloff; Denardin } \\
\text { (1994) }\end{array}$ & $\begin{array}{c}\text { Silva et al. } \\
\text { (1997) }\end{array}$ & $\begin{array}{c}\text { Wischmeier et al. } \\
\text { (1971) }\end{array}$ & $\begin{array}{c}\text { Denardin } \\
(1990)\end{array}$ & $\begin{array}{c}\text { Roloff; Denardin } \\
\text { (1994) }\end{array}$ & $\begin{array}{c}\text { Silva et al } \\
(1997)\end{array}$ \\
\hline & \multicolumn{8}{|c|}{ Fator LS ${ }^{(4)}$} \\
\hline PD1 & 2,12 & 9,55 & 97,13 & 4,78 & 2,59 & 11,67 & 118,67 & 5,84 \\
\hline PD2 & 0,43 & 2,59 & 76,85 & 3,89 & 0,53 & 3,16 & 93,89 & 4,75 \\
\hline PD3 & 1,68 & 5,05 & 76,99 & 3,79 & 2,06 & 6,17 & 94,07 & 4,63 \\
\hline PD4 & 0,62 & 8,61 & 109,53 & 5,54 & 0,75 & 10,53 & 133,82 & 6,77 \\
\hline PD5 & 2,37 & 8,87 & 108,24 & 5,32 & 2,89 & 10,84 & 132,24 & 6,50 \\
\hline PDR1 & 4,02 & 8,54 & 94,48 & 4,52 & 4,91 & 10,44 & 115,44 & 5,53 \\
\hline PDR2 & 0,46 & 4,56 & 81,17 & 4,10 & 0,56 & 5,57 & 99,17 & 5,01 \\
\hline PDI & 4,26 & 11,19 & 100,16 & 4,80 & 5,21 & 13,67 & 122,38 & 5,86 \\
\hline $\mathrm{CO} 1$ & 3,50 & 6,57 & 82,36 & 3,94 & 4,28 & 8,03 & 100,63 & 4,82 \\
\hline \multirow[t]{2}{*}{$\mathrm{CO} 2$} & 4,24 & 9,54 & 99,60 & 4,77 & 5,18 & 11,65 & 121,69 & 5,83 \\
\hline & \multicolumn{8}{|c|}{ Fator $\mathrm{LS}^{(5)}$} \\
\hline PD1 & 1,95 & 8,77 & 89,15 & 4,38 & 2,38 & 10,71 & 108,92 & 5,36 \\
\hline PD2 & 0,40 & 2,39 & 70,94 & 3,59 & 0,49 & 2,92 & 86,67 & 4,38 \\
\hline PD3 & 1,55 & 4,66 & 71,06 & 3,49 & 1,90 & 5,69 & 86,82 & 4,27 \\
\hline PD4 & 0,56 & 7,82 & 99,40 & 5,03 & 0,68 & 9,55 & 121,44 & 6,14 \\
\hline PD5 & 2,15 & 8,08 & 98,58 & 4,85 & 2,63 & 9,87 & 120,44 & 5,92 \\
\hline PDR1 & 3,70 & 7,86 & 86,96 & 4,16 & 4,52 & 9,61 & 106,24 & 5,09 \\
\hline PDR2 & 0,42 & 4,21 & 74,91 & 3,79 & 0,51 & 5,14 & 91,53 & 4,63 \\
\hline PDI & 3,91 & 10,27 & 91,91 & 4,40 & 4,78 & 12,54 & 112,30 & 5,38 \\
\hline $\mathrm{CO} 1$ & 3,21 & 6,01 & 75,36 & 3,61 & 3,92 & 7,35 & 92,08 & 4,41 \\
\hline $\mathrm{CO} 2$ & 3,91 & 8,80 & 91,93 & 4,40 & 4,78 & 10,75 & 112,32 & 5,38 \\
\hline
\end{tabular}

(1) PD: Plantio Direto; PDR: Plantio Direto Reiniciado; PDI: Plantio Direto iniciado a partir do convencional; CO: Plantio Convencional. (2) Média histórica com 7837,24 MJ mm ha-1 h-1. (3) Safra de 2003/2004 com 9575,41 MJ mm ha-1 h-1. (4) De acordo com Wischmeier; Smith (1978). (5) Bertoni; Lombardi Neto (1999).

Na Figura 3 são apresentadas às imagens referentes ao relevo das 10 parcelas experimentais na última safra. Observando a conformação da superfície das parcelas, notouse que todas apresentaram depressões ao longo da superfície.

Com o uso de modelos computacionais, foram percebidos caminhos preferenciais dentro dos sistemas que podem facultar em menor infiltração e na maior perda de solo. Comparando o sistema de cultivo com a modelagem da superfície nas parcelas tem-se no sistema PDR1 conformidade mais amena em relação ao PDR2; no PDR1 ocorreu menor perda de solo e água. Na parcela PDR2, indica caminho preferencial ao centro.

$\mathrm{Na}$ primeira e terceira safras há alto coeficiente de determinação correlação entre o volume escoado e a perda de solo $\left(\mathrm{R}^{2}=0,984\right.$ e 0,982 , respectivamente - Figura 3$)$. Considerando os resultados da última safra, na qual se verificou baixa correlação $(\mathrm{R} 2=0,393)$, os resultados indicam que o incremento na perda de solo pode decorrer da cobertura vegetal e da topografia das parcelas (Figura 4).
Na terceira safra, pode-se observar a perda média total de 3,467 tha ${ }^{-1}$ de solo nos sistemas PD, PDR e PDI. No sistema de plantio convencional (CO) houve perda de 29,23 $\mathrm{t} \mathrm{ha}^{-1}$ de solo, o que gerou a proporção de 1:8 entre os demais sistemas de plantio direto e o CO. Individualizando os sistemas, as proporções foram de 1:12,83, 1:11,63 e 1:1,97, respectivamente para PD, PDR e PDI, em relação ao sistema $\mathrm{CO}$.

Para as estimativas das perdas de solo usando a EUPS como modelo de predição, sendo utilizados os parâmetros de erodibilidade (estrutura granular pequena) e LS definidos em modelos matemáticos; a erosividade, determinada conforme Bertoni; Lombardi Neto (1999), e os fatores C e P para a cultura do algodoeiro, descritos por Margolis et al. (1985). Observou-se com o fator LS (BERTONI; LOMBARDI NETO, 1999) estimativas de perdas de solo menores em todos os modelos, com incremento nas estimativas de perdas de solo para a erosividade calculada durante um ano (Tabela 4). 
Os valores encontrados para a perda de solo com o K, proposto por Wischmeier et al. (1971), foram menores em comparação com aqueles obtidos quando se utilizou $\mathrm{K}=0,009$

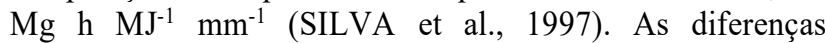
observadas em todas as situações podem estar associadas tanto à deficiência dos modelos em determinar a erodibilidade e aos fatores LS, bem como aos fatores $\mathrm{C}$ e $\mathrm{P}$ preconizados na literatura. Os resultados obtidos refletem a dificuldade de utilização da EUPS na estimativa da perda de solo, uma vez que existem dificuldadesinerentes à obtenção dos parâmetros necessários.

\section{CONCLUSÕES}

Nos dois primeiros anos de estudo (safras um e dois) as perdas de solo foram menores em comparação à última safra; o sistema de plantio direto mostrou-se mais eficiente quanto à conservação do solo e da água em relação aos outros sistemas empregados. A cobertura vegetal também influenciou nas primeiras safras em relação à cultura do algodão na última safra. O relevo das parcelas teve influência nas perdas de solo e água no sistema de plantio direto, uma vez que determinadas parcelas, independentemente da cobertura vegetal ou morta, obtiveram sistematicamente maiores perdas durante as três safras.

\section{REFERÊNCIAS}

AVANZI, J. C.; SILVA, M. L. N.; CURI, N.; NORTON, L. D.; BESKOW, S.; MARTINS, S. G. Spatial distribution of water erosion risk in a watershed with eucalyptus and Atlantic Forest. Ciência e Agrotecnologia, Lavras, v. 37, n. 5, p. 427-434, set./out. 2013. DOI: http://dx.doi.org/10.1590/S1413-70542013000500006

BERTONI, J.; LOMBARDI NETO, F. Conservação do solo. São Paulo: Ícone, 1999. 355 p.

BERTOL, I.; RAMOS, R. R.; BARBOSA, F. T.; GONZÁlEZ, A. P.; RAMOS, J. C.; BANDEIRA, D. H. Erosão hídrica em solo não preparado cultivado em contorno com uso de sistemas de cultivo solteiro e em consórcio. Revista Brasileira de Ciência do Solo, Viçosa, v. 37, n. 2, p. 521-528, mar./abr. 2013. DOI: http://dx.doi.org/10.1590/S0100-06832013000200023

DENARDIN, J. E. Erodibilidade do solo estimada por meio de parâmetros físicos e químicos. 1990. 81f. Tese (Doutorado) - Escola Superior Luiz de Queiroz, Piracicaba, 1990.

EMBRAPA_EMPRESA BRASILEIRA DE PESQUISA AGROPECUÁRIA. Sistema brasileiro de classificação de solos. 2. ed. Rio de Janeiro: Embrapa-CNPA, 2006. 306 p.

HUNINK, J. E.; DROOGERS, P.; KAUFFMAN, S.; MWANIKI, B. M.; BOUMA, J. Quantitative simulation tools to analyze up- and downstream interactions of soil and water conservation measures: Supporting policy making in the Green Water Credits program of Kenya. Journal of Environment Management, USA, v. 111, p. 187-194, 2012.

DOI: https://doi.org/10.1016/j.jenvman.2012.07.022

LOBATO, O. J. S. M. Disponibilidade e fórmula climatológica do Município de Goiânia e Municípios Limites. Manual da Escola de Agronomia e Veterinária. Goiânia (GO), v.2. n.1, p.76, 1978.
LU, C-X.; YU, G.; XIAO, Y.; XIE, G-D. Wind tunnel simulation and evaluation of soil conservation function of alpine grassland in Qinghai-Tibet Plateau. Ecological Economics, Amsterdam, v. 86, p. 16-20, 2013. DOI: https://doi.org/10.1016/j.ecolecon.2012.10.015.

MARGOLIS, E.; SILVA, A. B.; JACQUES, F. O. Determinação dos fatores da Equação Universal das perdas de solo para as condições de Caruaru (PE). Revista Brasileira de Ciência do Solo, Viçosa, v. 9, p. 165-169, 1985.

MARIOTI, J.; BERTOL, I.; RAMOS, J. C.; WERNER, R. S.; PADILHA, J.; BANDEIRA, D. H. Erosão hídrica em semeadura direta de milho e soja nas direções da pendente e em contorno ao declive, comparada ao solo sem cultivo e descoberto. Revista Brasileira de Ciência do Solo, Viçosa, v. 37, n. 5, p. 1361-1371, 2013. DOI: http://dx.doi.org/10.1590/S0100-06832013000500025

OLIVEIRA, F. P.; BUARQUE, D. C.; VIERO, A. C.; MERTEN, G. H.; CASSOL, E. A.; MINELLA, J. P. G. Fatores relacionados à suscetibilidade da erosão em entressulcos sob condições de uso e manejo do solo. Revista Brasileira de Engenharia Agrícola e Ambiental, Campina Grande, v. 16, n. 4, p. 337-346, abr. 2012. DOI: http://dx.doi.org/10.1590/S141543662012000400002

ROLOFF, G.; DENARDIN, J. E. Estimativa simplificada da erodibilidade do solo. In: REUNIÃO BRASILEIRA DE MANEJO E CONSERVAÇÃO DO SOLO E DA ÁGUA, 10., Florianópolis, 1994. Resumos expandidos... Florianópolis, SBCS, 1994. p. 150-151.

SHI, Z. H.; AI, L.; FANG, N. F.; ZHU, H. D. Modeling the impacts of integrated small watershed management on soil erosion and sediment delivery: A case study in the Three Gorges Area, China. Journal of Hidrology, Amsterdam, v. 438-439, p. 156-167, may. 2012. DOI: https://dx.doi.org/10.1016/j.jhydrol.2012.03.016

SILVA, M. L. N.; FREITAS, P. L.; BLANCANEAUX, P.; CURI, N.; LIMA, J. M. Relação entre os parâmetros da chuva e perdas de solo e determinação da erodibilidade de um Latossolo Vermelho-Escuro em Goiânia (GO). Revista Brasileira de Ciência do Solo, Viçosa, v. 33, n. 6, p. 1811-1820, nov./dez. 2009. DOI: http://dx.doi.org/10.1590/S0100-06832009000600029

VOLK, L. B. S; COGO, N. P. Erosão hídrica, em três momentos da cultura do milho, influenciada por métodos de preparo do solo e semeadura.Revista Brasileira de Ciência do Solo, Viçosa, v. 38, n. 2, p. 565-574, mar./apr. 2014. DOI: http://dx.doi.org/10.1590/S010006832014000200021

WISCHMEIER, W. H.; SMITH, D. D. Predicting rainfall erosion losses: A guide to conservation planning. Washington: Handbook. 1978. 57 p.

WISCHMEIER, W. H.; JOHNSON, C. B.; CROSS, B. V. A soil erodibility nomograph for farmland and construction sites. Journal of Soil and Water Conservation, Ankeny, v. 26, p. 189-193, 1971. 